\section{Mortality has improved in RA, but we must remain vigilant. Response to: 'Early intensive treatment normalises excess mortality in ACPA- negative RA but not in ACPA-positive RA' by Matthijssen et al}

We compliment Matthijssen et al with this highly interesting analysis and results from the Leiden Early Arthritis Clinic. Their mortality results strongly support our findings ${ }^{1}$ and again emphasise that the focus should be on the excess mortality that emerges after 10 years. Their data also suggest anti-CCP antibody (ACPA) is a strongly predictive factor for mortality.

The COBRA trial was performed before ACPA testing became available; however, we did run exploratory analyses on several prognostic factors, including rheumatoid factor which can be seen as a partial proxy for ACPA, and found the following to be predictors of increased mortality hazard: damage progression at 28 weeks; high Health Assessment Questionnaire (HAQ) score at baseline; shorter disease duration from start of complaints and absence of HLA-DR 2 or 3 (online supplementary appendix 1). ${ }^{2}$ Although rheumatoid factor did not come up as significant, our results suggest, as the Leiden results do, that there are subgroups of rheumatoid arthritis (RA) patients with severe disease that benefit less from early and more aggressive therapy.

However, we are a bit more optimistic about the results in the ACPA-positive group, and suggest some pessimism is perhaps induced by suboptimal scaling in the figures. Rates are best compared on a log scale. We redrew their figure on such a
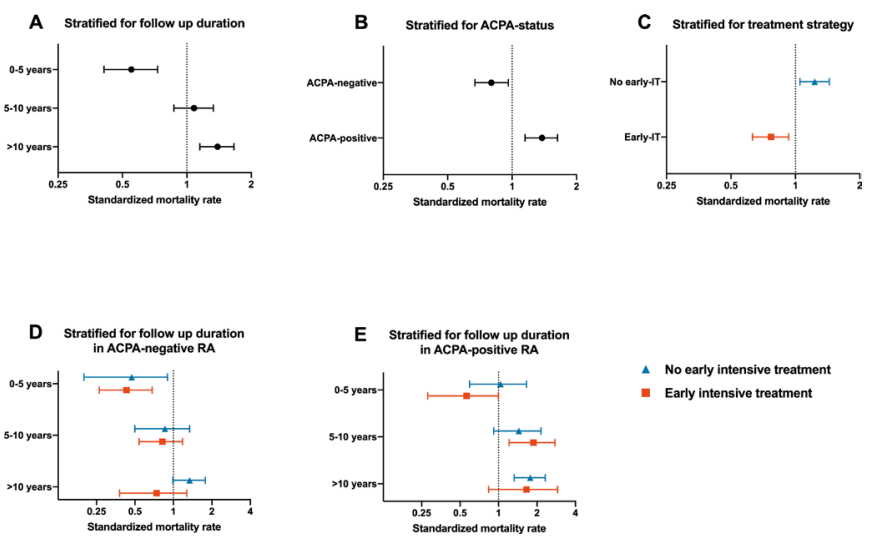

Figure 1 Mortality of patients with RA compared with the general population in the Leiden cohort, stratified for follow-up duration (A), disease subset characterised by ACPA-status (B), early intensive treatment $(I T)(C)$ and these variables combined $(D, E)$. Figure redrawn from Matthijssen et $a l^{2}$ with mortality rate depicted on a $\log (2)$ scale. scale, and made the scale similar for panels D and E (figure 1). The width of the error bars (95\% confidence interval, CI) now more accurately depicts the range on the relative scale of risk compared with unity. From our perspective, the development of mortality risk over time looks very similar in ACPA-negative and ACPA-positive patients, with a monotone increase of risk over time in patients without early intensive treatment, and a blunting of that increase in the intensively treated patients, suggesting that ACPA-positive patients also appear to benefit from early intensive treatment. Also note that the CI of the intensively treated ACPA-positive patients in the group followed $>10$ years overlaps unity, compatible with normalised mortality. Nevertheless, until more series are published with follow-up $>10$ years, we are best advised to monitor RA patients with poor prognosis closely, and be most aggressive in keeping their disease under control.

Pomme B M Poppelaars, ${ }^{1}$ Lilian H D van Tuyl, ${ }^{\oplus 1}$ Maarten Boers ${ }^{\oplus 1,2}$

${ }^{1}$ Rheumatology, Amsterdam Rheumatology and Immunology Centre - VU University Medical Centre, Amsterdam, The Netherlands

${ }^{2}$ Epidemiology and Biostatistics, VU University Medical Center, Amsterdam, The Netherlands

Correspondence to Professor Maarten Boers, Epidemiology \& Biostatistics, VU University Medical Center, Amsterdam 1081, Netherlands;

maartenguard-ard@yahoo.com

Handling editor Josef S Smolen

Funding The authors have not declared a specific grant for this research from any funding agency in the public, commercial or not-for-profit sectors.

Competing interests None declared.

Patient consent for publication Not required.

Provenance and peer review Commissioned; internally peer reviewed.

(C) Author(s) (or their employer(s)) 2019. No commercial re-use. See rights and permissions. Published by BMJ.

\section{A) Check for updates}

To cite Poppelaars PBM, van Tuyl LHD, Boers M. Ann Rheum Dis Epub ahead of print: [please include Day Month Year]. doi:10.1136/annrheumdis-2019-215863

Received 21 June 2019

Revised 24 June 2019

Accepted 26 June 2019

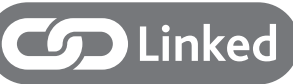

- http://dx.doi.org/10.1136/annrheumdis-2019-215843

Ann Rheum Dis 2019;0:1. doi:10.1136/annrheumdis-2019-215863

\section{REFERENCES}

1. Poppelaars PB, van Tuyl LHD, Boers M. Normal mortality of the COBRA early rheumatoid arthritis trial cohort after 23 years of follow-up. Ann Rheum Dis 2019;78:586-9.

2. Matthiissen $X M E$, Huizinga TWJ, Niemantsverdriet $E$, et al. Early intensive treatment normalises excess mortality in ACPA-negative RA but not in ACPA-positive RA. Ann Rheum Dis 2019:annrheumdis-2019-215843-2019. 